\title{
UFIIFAS NATIVE AND NONNATIVE CROCODILIANS OF FLORIDA
}

Florida has two native species of crocodilians, the American alligator (Alligator mississippiensis) and the American crocodile (Crocodylus acutus). These federally protected species are easily confused with nonnative crocodilians found in south Florida, such as the spectacled caiman (Caiman crocodilus) and the Nile crocodile (Crocodylus niloticus). Some key features used to distinguish these animals are the shape of the head, the shape of the snout, and the pattern of nuchal scutes (bony plates in between head and shoulders). It is important to report all nonnative crocodilians so that researchers may quickly remove them in order to protect Florida's native ecosystems.

\section{If you see a nonnative crocodilian:}

1. Take a photograph

2. Note the location

3. Report your sighting by calling 1-888-IVEGOT1, visiting www.IveGot1.org or by using the IveGot1 smartphone app (available for free at the iPhone App Store and Android Market).

All crocodile sightings (native and nonnative) should also be reported to University of Florida by calling (954) 577-6304.

\section{American alligator (Alligator mississippiensis) - NATIVE}
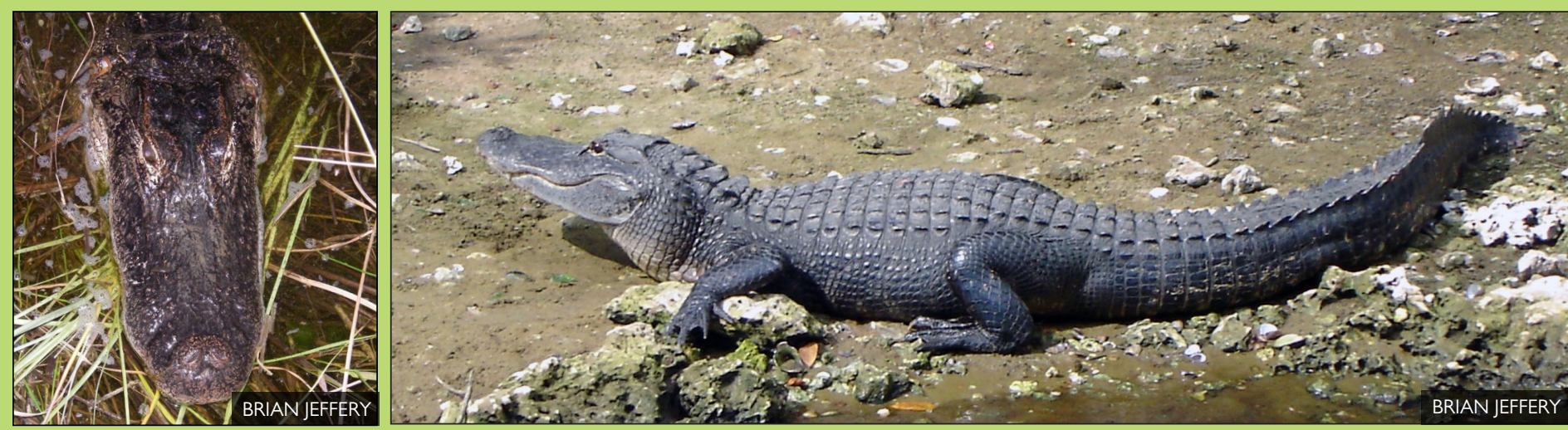

Very common in Florida; not necessary to report. Snout is much more broad and rounded than that of crocodiles; only the top row of teeth is visible when the mouth is closed. Adults are a dark, dusky olive-black color.

\section{Spectacled caiman (Caiman crocodilus) - NONNATIVE}
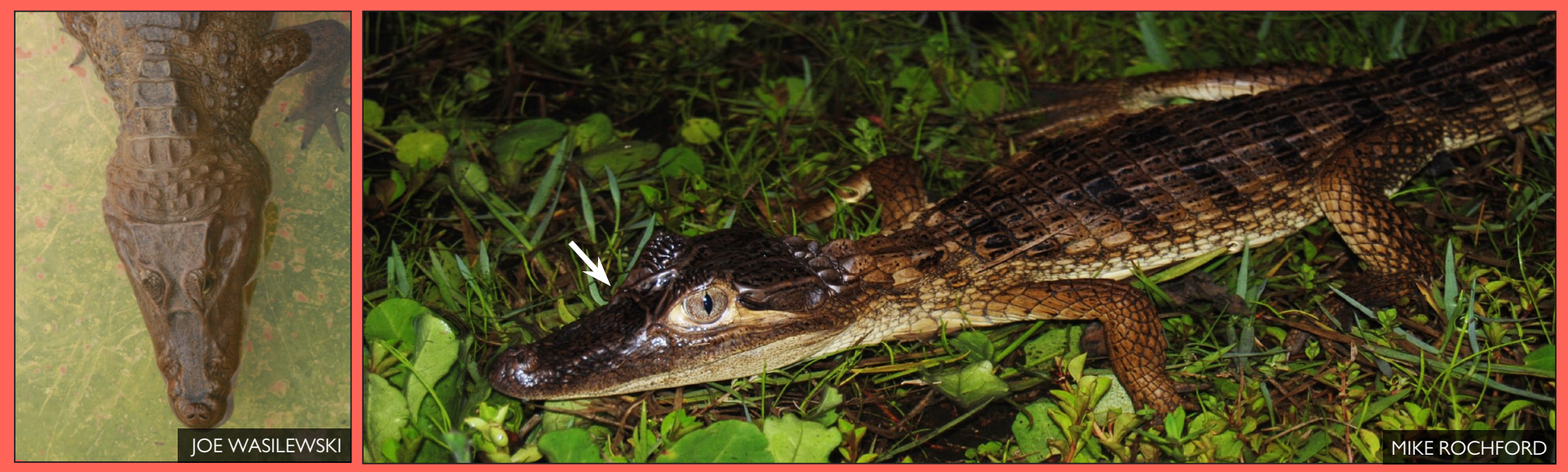

Please report to IveGot1! Similar to the American alligator but with a triangular head and slightly more pointed snout. "Spectacle" ridge on the snout in front of eyes. Dark brown or olive coloration. 


\section{Crocodiles of South Florida}

Crocodiles (left) are sometimes confused with alligators (right), however they are easily distinguishable by comparing their heads/snouts. Crocodiles have a pointed, narrow snout and their bottom teeth are visible when the mouth is closed. Alligators have a rounded, blunt snout and only the top teeth are visible when the mouth is closed.
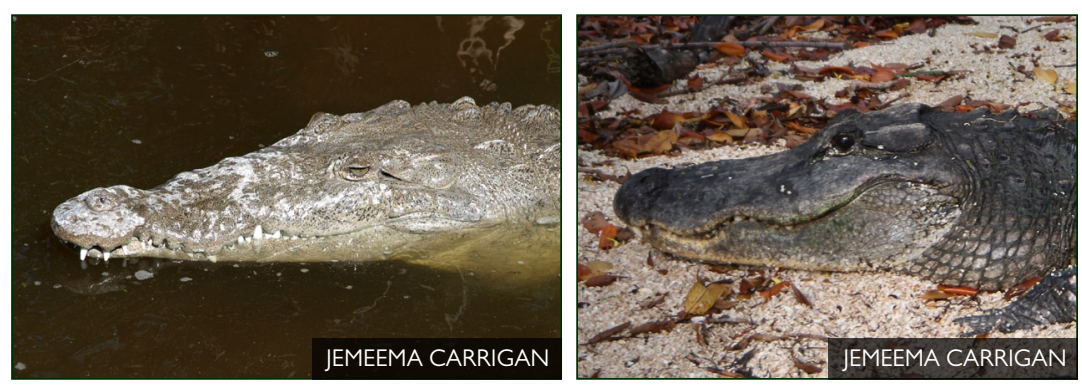

\section{American crocodile (Crocodylus acutus) - NATIVE}
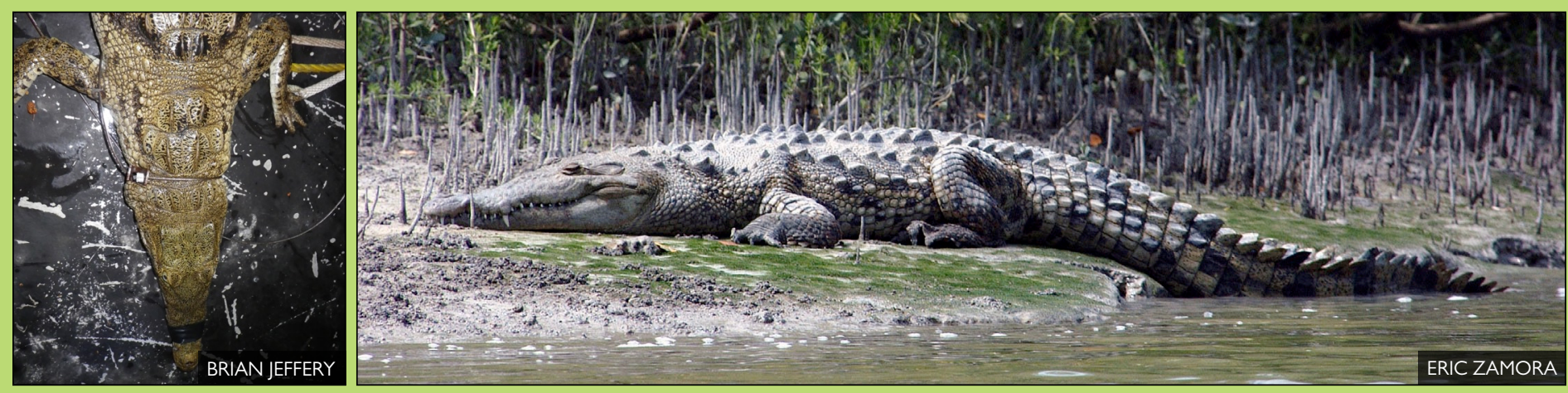

Please report to University of Florida. Narrow, pointed snout; fourth tooth on bottom row visible when the mouth is closed. Irregular pattern of nuchal scutes (bony plates in between head and shoulders). Dark olive-brown and dark olivegreen.

\section{Nile crocodile (Crocodylus niloticus) - NONNATIVE}
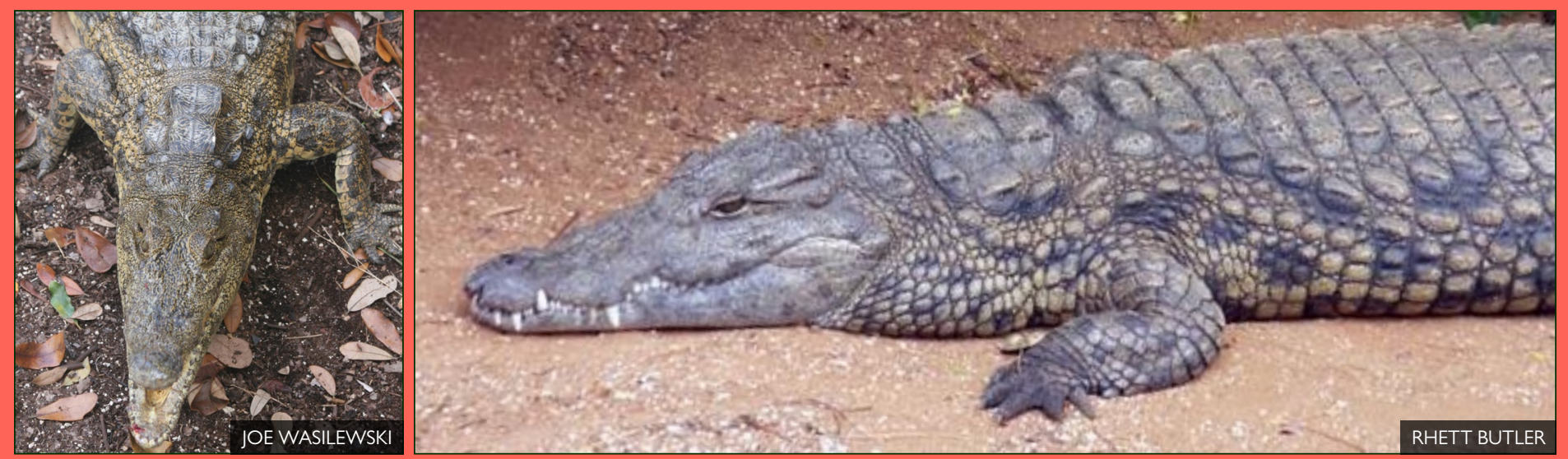

Please report to IveGot1 and University of Florida! Very difficult to distinguish from the American crocodile. Narrow, pointed snout (slightly more broad than an American crocodile). Symmetrical pattern of osteoderms (bony plates on the back). Dark olive-brown or dark gray. Not commonly found in south Florida. 